\title{
Do populismo às bandas cambiais: a evolução da política cambial no Chile de 1970 a 1999
}

\author{
PATRÍCIA HELENA F. CUNHA \\ PAULO GALA*
}

From populism to exchange rate bands: the evolution of exchange rate policy in Chile from 1970 to 1999 . We discuss in this paper the evolution of exchange rate policy in Chile since the seventies, with special attention to overvaluation and undervaluation cycles. Following a recent literature that argues in favor of competitive currencies as part of a development strategy, we argue that the Chilean exchange rate policy in the years that go from 1984 until 1999 were very important to its growth results. Chile even managed to go through the nineties without a major external crisis, especially when compared to its Latin American neighbors. We argue here that the exchange rate crawling band adopted in the middle eighties and nineties was important for its growth strategy.

Keywords: exchange rate policy; exchange rate levels; crawling bands; Chile.

JEL Classification: O11; F31; F4; F02.

\section{INTRODUÇÃO}

A experiência das políticas cambiais praticadas no Chile ao longo dos últimos trinta anos é especialmente interessante pois engloba praticamente todos os tipos de arranjos cambiais praticados na América Latina; desde a ancoragem cambial, passando por bandas estreitas e largas, até uma flutuação mais livre. Em termos de nível, os exemplos são também bastante ricos. O câmbio chileno passou por ciclos

\footnotetext{
* Respectivamente, Departamento de Economia da Pontifícia Universidade Católica - PUC, São Paulo. E-mail: paticunha@uol.com.br; e Escola de Economia de São Paulo - Fundação Getulio Vargas. E-mail: pgala@fgvsp.br. O artigo é uma versão ampliada e modificada de parte da tese de doutoramento do autor e de artigos anteriores da autora. Os autores agradecem ao parecerista anônimo desta revista. Submetido: Setembro 2006; Aprovado: Maio 2008.
} 
de sobrevalorização decorrentes do típico populismo latino-americano e das famosas âncoras cambiais voltadas para a estabilização de preços. Experimentou também níveis de relativa estabilidade e subvalorização no período de bandas, especialmente entre 1985 e 1995. Mais recentemente, com a livre flutuação a partir de 1999, o câmbio chileno primeiro se depreciou em virtude principalmente de uma série de choques externos e a partir de 2003 vem experimentando sucessivas apreciações.

A transição chilena de um regime de bandas cambiais ajustáveis para um de flutuação cambial no final dos anos 90 se destaca entre os países emergentes. Alguns aspectos desse processo são particularmente importantes: primeiro, não foi uma crise monetária e financeira ou um ataque especulativo que forçou o país a abandonar o sistema de bandas cambiais. A mudança para o regime de câmbio flutuante foi realizada em setembro de 1999 de forma voluntária pelo Banco Central e após os principais efeitos de contágio da crise asiática e russa já terem sido absorvidos pela economia. Segundo, as taxas de inflação foram reduzidas de um patamar em torno de $25 \%$ ao ano no início da década de 90 para taxas em torno de $3 \%$ ao ano no final dos 90 . Apesar da queda do PIB em 1999, a taxa de crescimento médio de toda a década foi de aproximadamente $6 \%$ ao ano, a mais elevada na América Latina. O país é, em geral, apresentado como um dos pioneiros na adoção de metas de inflação. O Banco Central do Chile anunciou a sua primeira meta de inflação em setembro de 1990 para o ano-calendário seguinte. No entanto, a experiência com as metas de inflação demonstra algumas peculiaridades e costuma ser dividido em duas fases. Na primeira, o sistema de metas de inflação coexistiu com alguns arranjos menos convencionais, como o regime de bandas cambiais deslizantes e mecanismos de controles de capitais. A segunda fase foi inaugurada com a adoção de taxas de câmbio flutuante.

O objetivo deste artigo é examinar a evolução da política cambial chilena, tanto em termos de níveis como de regimes, desde o início dos anos 70 até o final dos 90. Argumenta-se que as autoridades monetárias no Chile foram pragmáticas no sentido de adequar o seu regime cambial às circunstâncias mutáveis do ambiente macroeconômico interno e externo, logrando bastante sucesso em termos de desempenho de crescimento até quase o final da década de 90 . No entanto, como destaca Ffrench-Davis (2003), a perda de credibilidade do regime de bandas cambiais chileno que ocorreu no biênio anterior à crise da Ásia foi devida à má gestão do regime ao permitir a excessiva apreciação da taxa de câmbio real e elevação do déficit de transações correntes.

Cabe a observação de que a análise das consequências e dos desafios colocados com a adoção do regime de taxas de câmbio flutuante está além dos objetivos do artigo. A experiência chilena com o sistema de bandas é singular, uma vez que o Banco Central, independente desde 1990, possuía dois objetivos de política econômica que são entendidos em geral como simultaneamente conflitantes, a saber: 
uma meta de inflação e a defesa de um nível de câmbio real compatível com uma meta para o déficit de transações correntes.

O artigo está dividido em quatro seções, além dessa introdução. Na primeira seção apresenta-se um breve histórico da política cambial chilena com destaque para o populismo cambial praticado no período Allende, os esforços de estabilização do final dos anos 70 e início dos 80 , as metas de câmbios reais altos dos anos 80 e a transição para a flutuação nos 90 . Na seção seguinte discute-se a evolução do nível do câmbio real chileno, com destaque para a preocupação das autoridades em manter a competitividade da moeda após a desvalorização de 1982. Na terceira seção examinam-se as circunstâncias que implicaram o abandono do regime de bandas cambiais e a adoção do regime de flutuação cambial. Por último são apresentadas algumas considerações à guisa de conclusão.

\section{BREVE HISTÓRICO DA EVOLUÇÃO DA POLÍTICA CAMBIAL NO CHILE}

Allende assume o poder em 1970 e implanta um intenso programa populista. Introduz um congelamento de câmbio, redução de tarifas públicas e forte aumento dos salários públicos financiados por emissões monetárias. Como consequência, $\mathrm{o}$ déficit orçamentário passa de 2,7\% em 1970 para 10,7\% do PIB em 1971. O crédito e os salários reais se expandem fortemente e, partindo da utilização de capacidade instalada ociosa, a economia chilena apresenta taxa de crescimento de $9 \%$ em 1971, comparada a apenas 2,1\% em 1970. Em 1972, os desequilíbrios macroeconômicos decorrentes da política populista começam a surgir. O descasamento entre o lento crescimento da capacidade produtiva e o aumento da demanda acelera a inflação de $20 \%$ para $75 \%$ ao ano. As estatizações em diversos setores desestimulam a inversão privada. O excessivo aumento de importações esgota as reservas internacionais acumuladas até o início da década dos 70 levando a implantação de um sistema de controle cambial e aumento do mercado negro de divisas. Em 1973, a inflação atinge a marca de $361 \%$ e o PIB sofre uma queda de aproximadamente $5 \%$. Numa situação de inúmeros desequilíbrios econômicos e baixa governabilidade, Allende é derrubado por um golpe militar em setembro de 1973. Os elementos clássicos do populismo aparecem de forma bastante intensa nesse episódio: descontrole fiscal e sobrevalorização cambial ${ }^{1}$. O Gráfico 1 ilustra de forma clara o predomínio desse tipo de política cambial no período anterior ao golpe militar e a sua gradual reversão a partir de então.

O governo militar que assume o poder põe em prática um forte ajuste recessivo para controlar o desequilíbrio interno e externo no conhecido período liberal da primeira fase do governo Pinochet. Implanta um amplo programa de abertura comercial e financeira e privatiza o sistema de pensões. Reduz o déficit público de

\footnotetext{
${ }^{1}$ Ver Sachs (1991, p. 136) e Ffrench-Davis (2002, p. 24).
} 
25\% do PIB em 1973 para 2,5\% já em 1975. Implementa, além do controle fiscal, grande desvalorização do câmbio real visando ao ajuste externo. A queda do PIB em mais de 15 pontos percentuais no ano de 1975, com decorrente redução das importações e aumento das exportações, coloca a conta corrente numa posição superavitária em 1976. Apesar do forte controle fiscal, a inflação não cede, o que exige novas medidas de estabilização. A partir de 1978 o Chile passa a usar também o câmbio para controlar a inflação. Adota uma sucessão de "tablitas", anunciando e determinando previamente a trajetória da taxa de câmbio nominal com o objetivo de controlar a inflação via coordenação de expectativas. A política cambial passa a ser utilizada no combate à inflação através de apreciações periódicas. Em 1979, esse processo é intensificado com o congelamento da taxa de câmbio em 39 escudos por dólar, paridade mantida até 1982. Devido aos aumentos residuais de preços internos, observa-se no período a persistência de uma sobrevalorização da moeda chilena.

Gráfico 1: Evolução de câmbio real no Chile

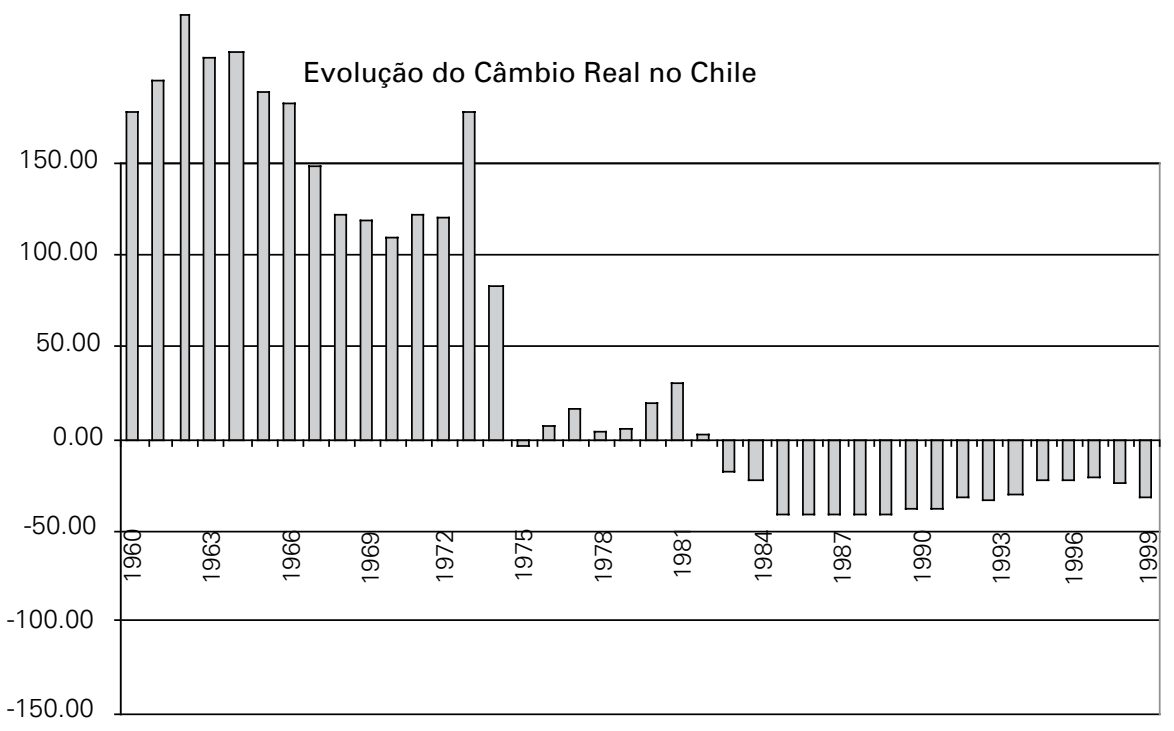

Obs.: Acima de 0 indica sobrevalorizações e abaixo de zero, subvalorizações. Fonte: Elaboração dos autores a partir de dados anuais de Easterly (2001).

Para se ter uma ideia da vulnerabilidade externa a qual estava sujeita a economia chilena, cabe lembrar que o elevado déficit de transações correntes em 1975 foi revertido em 1976, mas em 1978 já atingia o patamar de 7,1\% do PIB e em 1980 alcançava novamente o valor de $7,1 \%$ do PIB e aumenta para $14,5 \%$ do PIB em 1981 (Gráfico 2). No entanto, esses expressivos déficits deixaram de ser financiados com capitais voluntários a partir de 1982. A elevação das taxas de juros americanas e a moratória mexicana deflagraram a crise da dívida externa na América Latina que exigiu dos países o ajuste de seus balanços de pagamentos. O governo foi 
obrigado a abandonar o regime de câmbio fixo e promover uma maxidesvalorização cambial em meio a uma crise de balanço de pagamentos. Com o fracasso do plano de estabilização que deixou a economia numa profunda crise, o PIB teve uma queda em torno de $15 \%$ entre 1981 e 1982 e uma crise bancária se alastrou entre os bancos chilenos, que tiveram de ser socorridos pelo Banco Central ${ }^{2}$.

Desde então, os economistas e as próprias autoridades monetárias passaram a manifestar preocupações com a valorização da taxa de câmbio real e os déficits de transações correntes. A experiência fracassada com o regime de taxa de câmbio fixa durante 1979 e 1982 é recorrentemente citada como um experimento a não ser repetido. Como destaca Zahler (1998, p. 51), presidente do Banco Central do Chile no período entre 1991 e 1996, sobre um dos objetivos a serem perseguidos pela autoridade monetária:

la ley impone como objetivo el logro del equilibrio externo, lo que se interpretó como una afirmación de que el déficit en la cuenta corriente de la balanza de pagos importa, y de que es necesario asegurar que dicho déficit esté dentro de un rango preestablecido.

Meller (1997) e Morandé e Tapia (2002) destacam que a traumática experiência da crise de 1982 levou ao abandono da utilização da taxa de câmbio como âncora nominal desde 1983. A partir de então o objetivo da política cambial foi sendo adaptado aos objetivos perseguidos pela autoridade monetária segundo as condições econômicas mundiais, o ciclo econômico do país, os fluxos de capital externo e as imperfeições do mercado interno. Como salientam De Gregório et al. (2005, p. 2) sobre a finalidade do arranjo cambial pós-crise de 1982:

Después de una experiencia fallida de tipo de cambio fijo en 1982, que derivó en una devaluación y una recesión, se instauró un sistema de tipo de cambio reptante. Este tenía como objetivo implícito el promover un tipo de cambio real depreciado que estimulara las exportaciones y ayudara en la recuperación generando los recursos necesarios para pagar la enorme deuda externa.

Segundo Morandé (2001b) e Ffrench-Davis et al. (1997), a política macroeconômica para o período de 1985-1990 foi uma reação ao colapso sofrido em 19821983. Assim, a preocupação dominante a partir de 1985 não foi tanto reduzir a inflação, mas superar os problemas decorrentes dos elevados déficits de transações correntes (Gráfico 2) e da suspensão dos recursos externos voluntários.

\footnotetext{
${ }^{2}$ Para detalhes sobre como a crise bancária foi solucionada, ver: Sanhueza, G. Chilean Banking Crisis of the 1980's: solution and estimation costs. Banco Central do Chile, Documento de Trabajo, n. 104, Agosto 2001, 84p. Fugulin, Paulo J. A.; Carvalho, Carlos E. Intervenção estatal e superação da crise chilena do início da década de 1980. VI Congresso Brasileiro de História Econômica, 2005, Conservatória. Anais do VI Congresso Brasileiro de História Econômica. Conservatória: Associação Brasileira de Pesquisadores em História Econômica ABPHE, 2005.
} 
Na segunda fase do governo Pinochet, que vai de 1982 a 1990, a condução da política econômica assume, portanto, um tom mais pragmático, abandonando muito dos exageros ortodoxos do período anterior. O Banco Central passa a adotar uma política de minidesvalorizações cambiais que visava manter o câmbio em linha com o diferencial de inflação interna e externa, mantendo a competitividade da economia chilena. Introduz uma banda de variação cambial que iria durar, apesar de diversos ajustes, até $1999^{3}$. Várias desvalorizações discretas ao longo dos 80 contribuíram para uma depreciação real do câmbio chileno de aproximadamente $130 \%$ entre 1982 e 1988 . No final dos 80 , observa-se uma pequena apreciação do câmbio decorrente de grandes aumentos do preço internacional do cobre. Com a aceleração do nível de atividade econômica, o balanço de pagamentos chileno passa a apresentar déficits em 1989 e 1990 que acabam por colocar de novo o câmbio no teto da banda ${ }^{4}$.

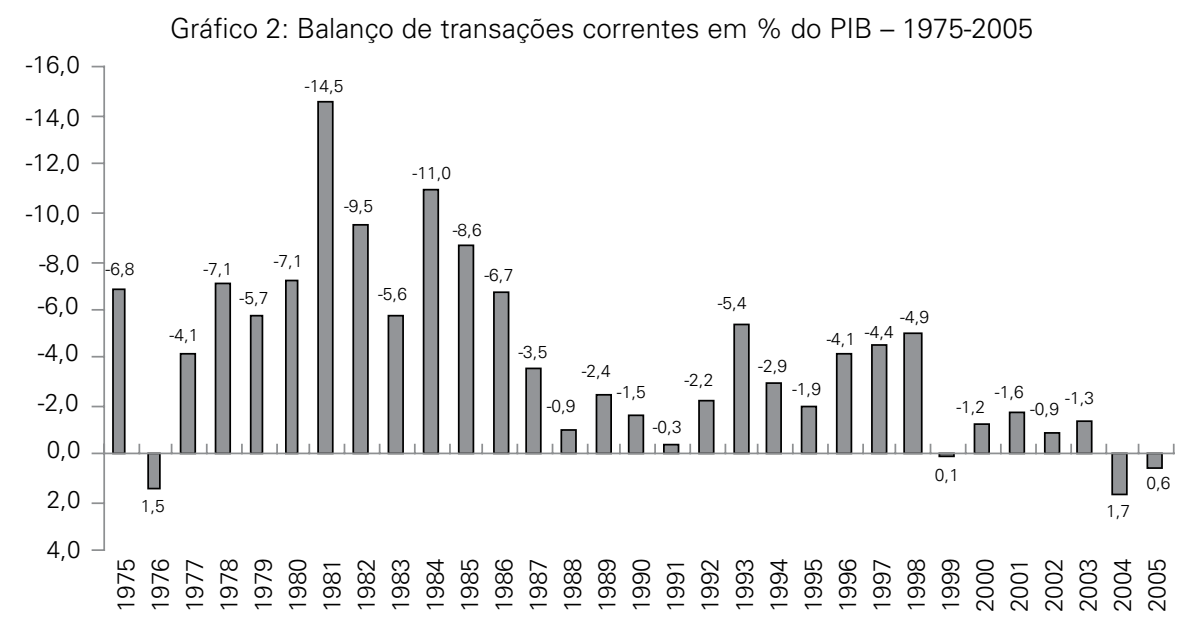

Obs.: São déficit os valosres acima de zero e valores negativos. Fonte: World Development Indicators, 2006.

O sistema de bandas cambiais ajustáveis foi adotado em agosto de 1984, acompanhado da manutenção das minidesvalorizações do centro da banda, promovidas para descontar a inflação externa e interna. No regime de bandas cambiais deslizantes, a taxa de câmbio flutua dentro do intervalo da banda, mas o Banco Central está comprometido com a intervenção quando a taxa atinge o piso ou o teto da banda. Esse regime se tornou popular entre os países emergentes nos anos 90 porque parecia combinar as vantagens dos regimes de câmbio fixo e flutuante $^{5}$. Durante os anos 80 foram implementadas, em adição às minidesvaloriza-

\footnotetext{
${ }^{3}$ Para uma análise da bem-sucedida administração do sistema de bandas cambiais no Chile e Colômbia nesse período, ver Williamson (1996).

${ }^{4}$ Ver Ffrench-Davis 2002, p. 148.

${ }^{5}$ O Sistema Monetário Europeu inaugurado em 1979 constituiu uma experiência importante de regime
} 
ções diárias que seguiam a regra de paridade de poder de compra, várias desvalorizações discretas, uma vez que o objetivo era manter a competitividade da economia. Em setembro de 1984, o centro da banda, denominada de taxa acuerdo, foi desvalorizado em $23,7 \%$. Nova desvalorização de $9,1 \%$ aconteceu em fevereiro de 1985 , e outra de $8,5 \%$ em julho de 1985 . Há praticamente um consenso na literatura que ocorreu uma expressiva desvalorização efetiva da moeda chilena no período. O regime de bandas inicia-se com bandas bastante estreitas, $\pm 0,5 \%$. No entanto, o intervalo das bandas de flutuação foi ampliado periodicamente, com exceção de um breve período em 1998. Em julho de 1985, a amplitude permitida aumentou para $4 \%$. Entre janeiro de 1988 e maio de 1989, o intervalo da banda estendeu-se para $\pm 3 \%$ e a partir de junho de 1989 ampliou-se para $\pm 5 \%$.

$\mathrm{Na}$ década de 90 , o regime de bandas foi se adequando às alterações na conjuntura interna e internacional. O ano de 1990 marcou o início do novo governo democrático que estabeleceu como objetivos principais de política macroeconômica a redução da inflação e a manutenção do setor externo como motor do crescimento econômico. No cenário externo, merece destaque o fim do racionamento e o excesso de liquidez no mercado internacional, o que levou a um grande fluxo de capitais direcionados às economias emergentes.

Se, por um lado, a política cambial para o período 1985-1990 teve como objetivo manter o câmbio real depreciado para estimular as exportações e permitir a recuperação da economia após a severa recessão, por outro, no início dos anos 90, com o forte influxo de capitais para a economia chilena, a meta de taxa de câmbio real se tornou mais difícil de ser obtida e foi alterada para um alvo de déficit de transações correntes sustentáveis. Para a primeira metade da década de 90 buscou-se manter o déficit em conta corrente em torno de $3 \%$ a $4 \%$ do PIB. Para o período entre 1996 e 1998, o número perseguido pelas autoridades situava-se entre $4 \%$ e $5 \%$ do PIB. Os dados apresentados no Gráfico 2 mostram que os valores estiveram relativamente próximos da meta perseguida. A média do déficit no período 1990-1995 foi de -2,3\% do PIB, abaixo do alvo. Entre os anos de 1996 e 1998, o déficit de transações correntes médio foi de $-4,5 \%$, e apresenta uma tendência crescente.

As mudanças ocorridas no mercado internacional, as eleições democráticas do presidente Aylwin e as altas taxas de juros reais provocaram não só a volta da economia chilena ao mercado financeiro internacional, como deixaram o país muito atrativo para o capital internacional. É neste contexto que outras medidas pouco convencionais foram implementadas com o objetivo de lidar com as pressões para valorização da taxa de câmbio que poderiam comprometer a competitividade e, consequentemente, o crescimento da economia. Além do acúmulo de reservas internacionais que levaram as autoridades monetárias a esterilizar essas operações para que elas não significassem descontrole da inflação, em 1991, o

\footnotetext{
de bandas cambiais. Para detalhes, ver: Eichengreen, B. The EMS in Retrospect. Prepared for the conference celebrating the 75th anniversary of the Banco de Mexico, Mexico City, 14-15 November, 2000, $65 \mathrm{p}$.
} 
Banco Central impôs controles à entrada de capitais de curto prazo. Foi introduzida uma taxa de depósito obrigatório não remunerado para o período de um ano para todo o capital de curto prazo que ingressasse no país. A taxa inicial de $20 \%$ foi elevada para $30 \%$ em 1992, reduzida para $10 \%$ em junho de 1998 e eliminada ainda em 1998 em decorrência da forte redução dos fluxos de capitais.

Não obstante os controles à entrada na primeira metade da década de 90 , as autoridades monetárias liberalizaram significativamente as saídas de capitais no período; os exportadores, por exemplo, não se viram mais obrigados a trazer para o país os recursos advindos de suas exportações.

Conforme indica o Gráfico 3, apesar das medidas acima citadas para mitigar a valorização do câmbio real, a taxa de câmbio nominal permanecia muito próxima do piso da banda. Esse fato gerava pressões especulativas no mercado cambial.

Gráfico 3: Taxa de câmbio nominal e bandas cambiais 1982-2004

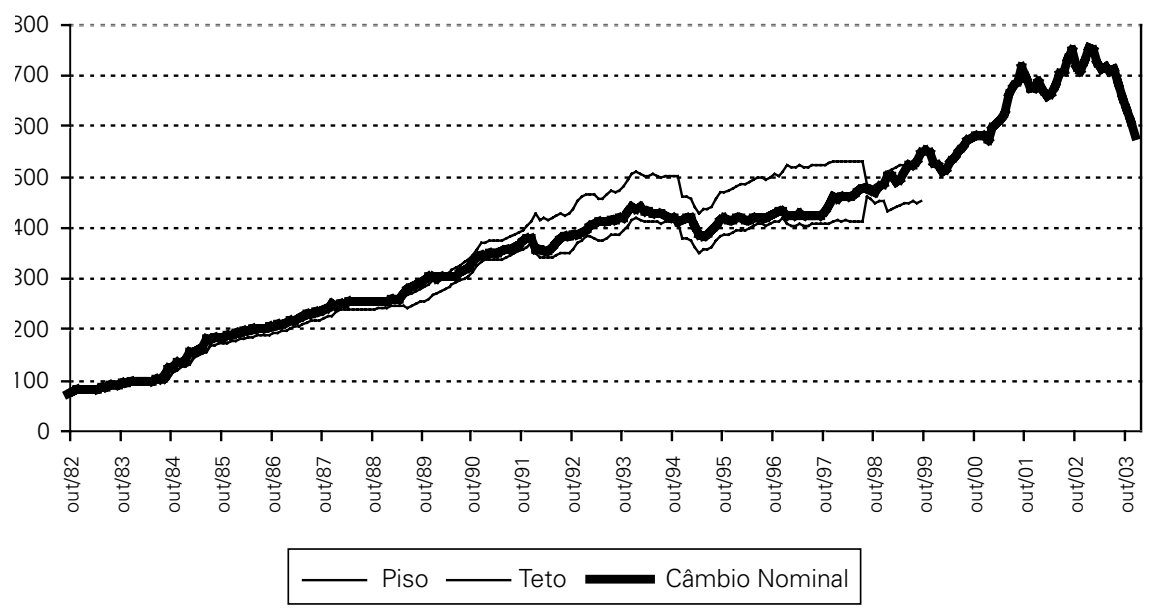

Fonte: Banco Central do Chile. Base de Dados Econômicos.

Em 1992, o Banco Central abandonou a política de flutuação pura dentro da banda e adotou o esquema de flutuação suja, permitindo que a taxa de câmbio nominal oscilasse entre $1 \%$ e $8 \%$ do limite da banda. Diferentemente da década anterior, na década de 90 ocorreram valorizações discretas no centro da banda à medida que a taxa de câmbio nominal insistia em permanecer muito próxima do piso (Quadro 1). Como já salientamos, os reajustes no centro da banda foram realizados segundo a regra de paridade de poder de compra. Em novembro de 1994 foi reduzida a ponderação do dólar na cesta de moedas para $50 \%$, posteriormente $45 \%$, e em 1997 aumentada para $80 \%$. Os objetivos dessas medidas eram, de um lado, introduzir maior incerteza na taxa de câmbio de curto prazo ao desestimular a arbitragem de taxas de juros e, de outro, manter mais estável o retorno em peso das exportações, uma vez que as transações comerciais eram diversificadas geograficamente. As outras moedas consideradas eram o yen japonês e o marco alemão. 
A inflação estrangeira considerada para o cálculo foi inicialmente de 3,6\%, chegando a $0 \%$ em alguns períodos. Em dezembro de 1995 foi incluída na regra que determinava o centro da taxa, uma apreciação real anual de $2 \%$ a título de ganhos de produtividade.

Quadro 1: Ajustes do centro da banda cambial

\begin{tabular}{ccc}
\hline Data & Variação & Sinal \\
\hline set/84 & $23,70 \%$ & Desvalorização \\
$\mathrm{fev} / 85$ & $9,10 \%$ & Desvalorização \\
jul/85 & $8,50 \%$ & Desvalorização \\
abr/91 & $1,40 \%$ & Valorização \\
jun/91 & $2,00 \%$ & Valorização \\
jan/92 & $5,00 \%$ & Valorização \\
dez/94 & $9,70 \%$ & Valorização \\
jan/97 & $4,00 \%$ & Valorização \\
\hline
\end{tabular}

O Quadro 2 sistematiza as características das bandas de flutuação da taxa de câmbio nominal. Depreende-se que a década de 90 inicia-se com bandas de $\pm 5 \%$ e, em janeiro de 1992, a diferença entre o piso e o teto da banda já estava em $20 \%$. Em final de junho de 1998, a banda de flutuação foi reduzida para o teto de $3 \%$ e piso de $2,5 \%$. O motivo de tal medida foi conter a pressão especulativa decorrente dos efeitos da crise asiática. Segundo Morandé e Tapia (2002) foi uma decisão arriscada, mas a autoridade monetária conseguiu coordenar as expectativas e impedir a ocorrência de uma depreciação violenta da moeda chilena.

Quadro 2: Resumo das características da banda de flutuação da taxa de câmbio nominal 1984-1999

\begin{tabular}{|c|c|c|c|c|c|c|}
\hline \multirow[t]{2}{*}{ Data } & \multirow[t]{2}{*}{ Amplitude } & \multicolumn{3}{|c|}{$\begin{array}{l}\text { Composição da } \\
\text { cesta de moedas }\end{array}$} & \multirow[t]{2}{*}{$\begin{array}{l}\text { Inflação externa } \\
\text { para ajuste }\end{array}$} & \multirow[t]{2}{*}{$\begin{array}{l}\text { Apreciação real } \\
\text { (produtividade) }\end{array}$} \\
\hline & & US\$ & Yen & Marco & & \\
\hline ago/84 - jun/85 & $\pm 0,5 \%$ & $100 \%$ & $0 \%$ & $0 \%$ & $3,6 \%$ & $0 \%$ \\
\hline jul/85 - dez/87 & $\pm 2 \%$ & $100 \%$ & $0 \%$ & $0 \%$ & $3,6 \%$ & $0 \%$ \\
\hline jan/88 - mai/89 & $\pm 3 \%$ & $100 \%$ & $0 \%$ & $0 \%$ & $3,6 \%$ & $0 \%$ \\
\hline jun/89 - fev/91 & $\pm 5 \%$ & $100 \%$ & $0 \%$ & $0 \%$ & $3,6 \%$ & $0 \%$ \\
\hline mar/91 - jun/91 & $\pm 5 \%$ & $100 \%$ & $0 \%$ & $0 \%$ & $0 \%$ & $0 \%$ \\
\hline jun/91 - nov/91 & $\pm 5 \%$ & $100 \%$ & $0 \%$ & $0 \%$ & $3,6 \%$ & $0 \%$ \\
\hline dez/91 - dez/91 & $\pm 5 \%$ & $100 \%$ & $0 \%$ & $0 \%$ & $2,4 \%$ & $0 \%$ \\
\hline jan/92 - abr/92 & $\pm 10 \%$ & $100 \%$ & $0 \%$ & $0 \%$ & $2,4 \%$ & $0 \%$ \\
\hline mai/92 - jun/92 & $\pm 10 \%$ & $100 \%$ & $0 \%$ & $0 \%$ & $1,2 \%$ & $0 \%$ \\
\hline jul/92 - nov/94 & $\pm 10 \%$ & $50 \%$ & $20 \%$ & $30 \%$ & $2,4 \%$ & $0 \%$ \\
\hline dez/94 - nov/95 & $\pm 10 \%$ & $45 \%$ & $25 \%$ & $30 \%$ & $2,4 \%$ & $0 \%$ \\
\hline dez/95 - dez/96 & $\pm 10 \%$ & $45 \%$ & $25 \%$ & $30 \%$ & $2,4 \%$ & $2 \%$ \\
\hline jan/97 - jul/98 & $\pm 12,5 \%$ & $80 \%$ & $5 \%$ & $15 \%$ & $2,4 \%$ & $2 \%$ \\
\hline
\end{tabular}




\begin{tabular}{lcccccc}
\hline jul/98 - set/98 & $-3 \% ;+2,5 \%$ & $80 \%$ & $5 \%$ & $15 \%$ & $2,4 \%$ & $0 \%$ \\
set/98 - dez/98 & $\pm 3,5 \%$ & $80 \%$ & $5 \%$ & $15 \%$ & $0 \%$ & $0 \%$ \\
dez/98 - set/99 & $\pm 8 \%$ & $80 \%$ & $5 \%$ & $15 \%$ & $0 \%$ & $0 \%$ \\
\hline
\end{tabular}

Fonte: Morande \& Tapia, 2002.

A tentativa de conduzir a política cambial de forma a manter a competitividade externa não impediu que o peso chileno se apreciasse nos anos 90 , conforme mostra o Gráfico 4. A apreciação real da taxa de câmbio acabou favorecendo o controle das taxas de inflação. Parte da apreciação real observada nos anos 90 foi certamente uma decorrência de mudanças estruturais experimentada pela economia chilena desde o final dos 80 . Ffrench-Davis $(2004$, p. 209) destaca, entretanto, que o resultado das políticas praticadas nos anos 90 foi uma apreciação cambial relativamente muito menor no Chile do que no resto da América Latina. Em 1994 a taxa de câmbio real chilena havia se apreciado em 3,6\% em relação à média do período 1987-1990, enquanto para o resto da América Latina esse percentual era de 24\%. Entretanto, no período 1995-1997, a continuidade do fluxo de capitais e um afrouxamento da postura de intervenção do Banco Central fizeram com que o câmbio se apreciasse em termos acumulados $16 \%$ até que a crise asiática desencadeasse uma fuga de capitais com nova desvalorização do câmbio real.

Gráfico 4: Taxa de câmbio observado e taxa de câmbio real - jan. 1986 a dez. 2007 - Chile

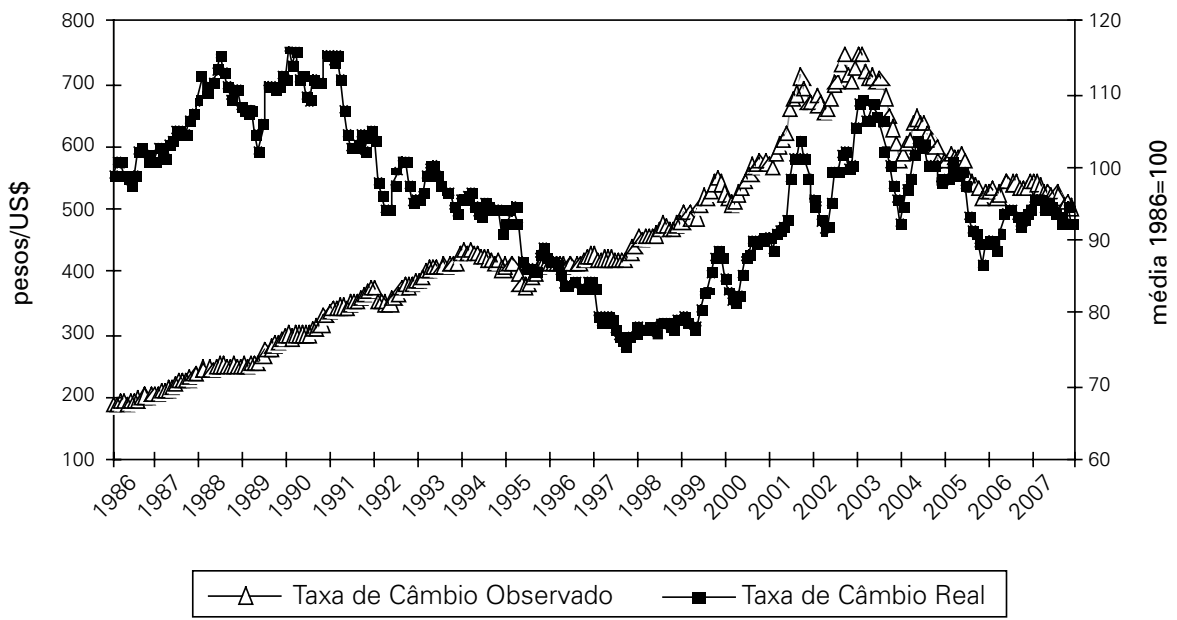

Obs.: A diminuição dos valores indica apreciação do câmbio nominal e real.

(1) Taxa de câmbio observado (eixo esquerdo) se refere à média das transações no mercado interbancário do dia anterior.

(2) O índice de taxa de câmbio real observado, TCR (eixo direito) se define como a taxa de câmbio nominal observado multiplicado pelo quociente entre a inflação externa relevante e o IPC. A inflação externa é calculada com os IPM expressos em dólares dos principais sócios comerciais ponderando a importância relativa das importações e exportações, excluindo o petróleo e o cobre.

Fonte: Banco Central do Chile. 
O Chile tentou manter a competitividade de sua economia e impedir que a valorização cambial comprometesse suas exportações. Até a crise da Ásia em 1997, as taxas de crescimento anuais das exportações se mantiveram um pouco superiores a $10 \%$ ao ano, com exceção de 1990 , quando a taxa cresceu $8,6 \%$ ao ano. A redução nas taxas no pós-1997 é explicada pelo fato de os países asiáticos serem importantes parceiros comerciais do Chile e também pelo desaquecimento da economia mundial. Segundo Morandé (2002, p. 589), no período final do regime de bandas cambiais, quando ocorria conflito em relação a qual objetivo a autoridade monetária deveria priorizar, a meta de inflação ou a meta de déficit de transações correntes, a escolha era sempre pela primeira.

\section{EVOLUÇÃO DO NÍVEL DO CÂMBIO REAL NO CHILE}

O gráfico 1 apresenta a evolução do câmbio real chileno em relação ao dólar americano a partir dos dados de Easterly (2001) para o período 1970-1999. Posições acima de zero apontam para sobrevalorizações e abaixo para subvalorizações. A desvalorização no meio da década dos anos 70 e a apreciação do peso no início dos 80 aparecem claramente. A mudança de patamar ocorrida a partir de meados dos anos 80 fica também bastante evidente.

A meta de déficit em contas correntes abaixo de $5 \%$ do PIB seguida nos anos 90 indica a preocupação do governo do Chile em relação à competitividade da moeda. Refletindo sobre a política cambial chilena, Morandé e Tapia (2002) destacam as preocupações das autoridades chilenas ao administrar a banda cambial nos 80 e 90. Apesar de ter sido alterada por várias vezes e de conter um componente de ajuste de produtividade, a banda mostra o objetivo das autoridades de administrar o nível do câmbio real. Tinha por meta evitar os problemas das estabilizações baseadas em âncoras nominais e coordenação de expectativas como no caso das "tablitas" do final dos 70 ou ainda da fixação do peso a partir de 1979.

The fact that the band's center followed the difference between domestic and external inflation reveals that there was a concern with misalignments of the real exchange rate with respect to a PPP concept, as well as an attempt to manage - at least partially - the real exchange rate (Morandé e Tapia, 2002, p. 1).

Segundo Zahler (1998), entre os critérios que nortearam as metas de déficits para transações correntes destacam-se: os objetivos de manter estáveis ou melhorar os indicadores de solvência externa; a sustentação de níveis de reservas internacionais que não comprometessem o financiamento externo de médio e longo prazos; a redução dos riscos de reversão da liquidez internacional. A ênfase no controle do déficit de transações correntes se explica pelo papel da restrição externa na história da economia chilena e pelo entendimento das autoridades econômicas de que a poupança externa deveria complementar a poupança interna, ou 
seja, o crescimento econômico deveria ser financiado principalmente por recursos internos ${ }^{6}$.

Ao analisar três décadas de política econômica no Chile, Ffrench-Davis (2004) discute a evolução da política cambial. Trata da influência das duas grandes reformas comerciais dos anos 70 e 80 no desempenho exportador chileno e destaca a importância da depreciação relativa do câmbio real após a crise da dívida externa. Nos anos 70 e início dos 80 , a moeda chilena passou por dois grandes ciclos de apreciação resultantes do período populista da primeira metade da década e dos esforços de estabilização da segunda metade dos 70 , como vimos. Apesar da abertura comercial e de políticas com vistas a melhorar o desempenho do setor externo, o estímulo exportador foi fortemente prejudicado pelo comportamento da taxa de câmbio. Na segunda reforma comercial dos 80 , a desvalorização real do câmbio contribuiu fortemente para o impulso exportador. Desde então, o Banco Central teria passado a adotar uma postura mais intervencionista no mercado cambial com vistas a evitar apreciações (Ffrench-Davis, 2004, p. 205). Como destaca o autor, o setor de exportações não tradicional, ligado principalmente à indústria, atingiu um percentual de $20 \%$ no total das exportações em 1989, saindo da casa dos $8 \%$ em meados dos anos 70 .

Ainda sobre esse ponto, Ffrench-Davis conclui que o sucesso exportador dos últimos anos esteve fundamentalmente relacionado à política de câmbio relativamente desvalorizado.

Em suma, durante las três ultimas décadas Chile presenció um período de excepcional crecimiento de sus exportaciones. Tan notable desempeño estuvo asociado, durante lãs últimas dos décadas, a políticas heterodoxas más bien activas que procuraron preservar um tipo de cambio real competitivo y generar capacidad exportadora, en contraste com la implantación, unicamente, de reformas económicas ortodoxas, como ocurrió em los setenta (Ffrench-Davis, 2004, p. 225)

O crescimento médio das exportações chilenas no período 1960-1973 foi de 3,5\%, mantendo-se nesse nível entre 1973 e 1983 e saltando para 5,5\% entre 1983 e 2002 (Alvarez, 2004, p. 123)

Outros autores também destacam a superioridade da política cambial chilena. Montiel (2003, p. 427) chama a atenção para essa trajetória, ressaltando sua superioridade em relação ao episódio mexicano no início dos 90 e da Tailândia em meados da década. Cardoso (2003) destaca a proximidade entre a condução cambial na Coreia do Sul e no Chile mais recentemente e chama a atenção para a importância da manutenção de um câmbio competitivo nas estratégias de desenvolvimento de ambos. Dornbusch et al. (1995) comparam o desempenho chileno com o mexicano

\footnotetext{
${ }^{6}$ Segundo Zahler (1998, p. 54), a poupança interna foi de $10 \%$ do PIB no período de 1980-1985, quase $24 \%$ do PIB em 1989 e acima de 25\% entre 1992 e 1996.
} 
depois da crise da dívida. Destacam a política cambial competitiva praticada pelo Chile como um dos principais fatores responsáveis pelo seu sucesso comparado ao relativo fracasso mexicano com novo episódio de apreciação e crise no início dos 90. As trajetórias de crescimento e de emprego de ambas as economias teriam sido fortemente afetadas pela política cambial (Dornbusch et al. 1995, p. 259).

O Gráfico $5^{7}$, construído a partir da base de dados de Easterly (2001) e de um índice construído para o Brasil, mostra a evolução das taxas de câmbio real do Brasil, Argentina, México, Colômbia e Chile tomando-se por base o ano de 1979. A série mostra a diferença de condução de política cambial entre esses países nos últimos vinte anos. A crise da dívida no início dos 80 resultou em depreciações reais para as cinco economias. Em meados dos 80 , os câmbios reais chileno e colombiano começaram a se descolar da trajetória dos outros três países que ingressaram nos seus já conhecidos ciclos de apreciação e crise dos 90. Após a crise do final de 1994 e início de 1995 no México, os câmbios brasileiro e argentino seguem numa trajetória de apreciação e a partir de 1997 o câmbio mexicano volta a se apreciar gradualmente. O câmbio chileno passa por uma leve apreciação até que volta a se depreciar na crise asiática.

Gráfico 5: Evolução de câmbio real para países da América Latina

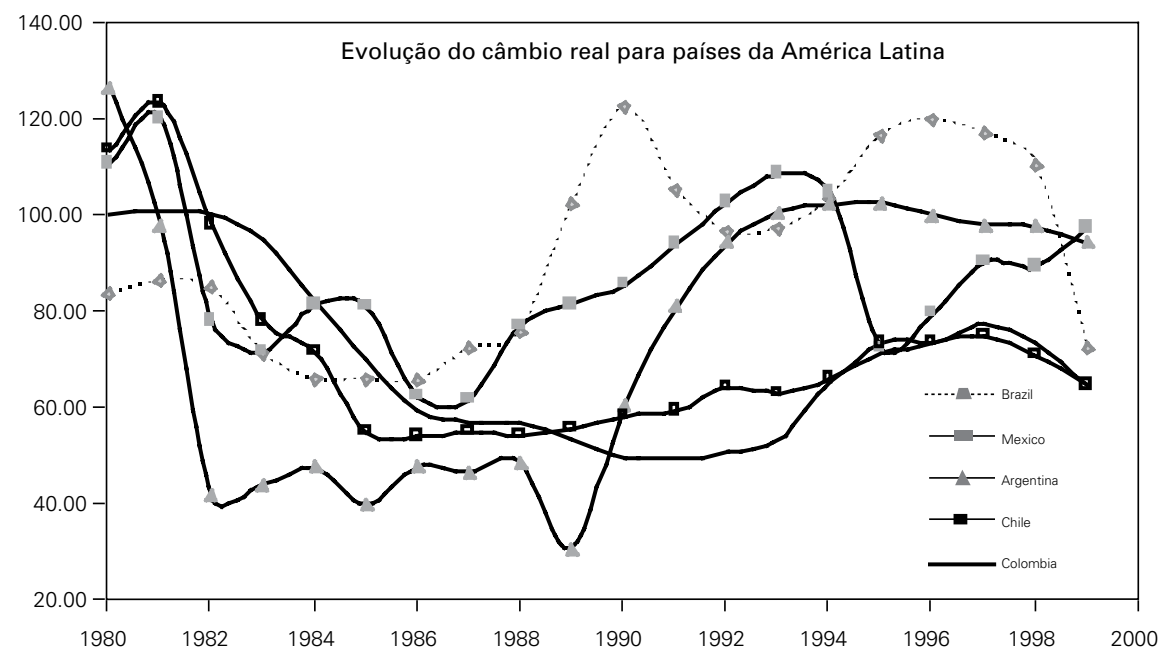

Obs.: Diminuição do índice indica depreciação real da moeda e aumento apreciação real.

Fonte: Elaboração dos autores a partir de dados anuais de Easterly (2001).

Num livro que trata da viabilidade de crawling bands em países em desenvolvimento, Williamson (1996) discute a importância da política cambial na "luta

\footnotetext{
${ }^{7}$ Para o Chile, o Gráfico 5 mostra uma estabilidade da taxa de câmbio real e deixa a apreciação dos anos 90 menos visível que no Gráfico 4 (construído a partir do índice de câmbio real fornecido pelo Banco Central) por causa da escala utilizada para sua construção.
} 
contra a Dutch Disease" que provoca a retração do setor de bens comercializáveis responsável, no mais das vezes, por um maior dinamismo tecnológico. No estudo de caso que apresenta sobre o Chile, destaca a preocupação das autoridades na administração do câmbio na presença de grandes influxos de capitais em meados dos anos 90 .

Chile emerged from the 1982 crisis with a strong national consensus that Dutch disease is indeed dangerous. Although that consensus seems to be beginning to fray in the financial sector, it still dominates the thought of the policymaking community. The implication is that the Chilean authorities will not revise the target current account deficit upward, or at least not by enough to resolve the tension. The options that leaves are to continue sterilizing a large part of the inflow, to reduce the incentive for the inflow by lowering the interest rates in Chile, to choke off more of the inflow through tighter capital controls, or to increase the outflow (Williamson, 1996, p. 30).

\section{A CRISE DE 1997-1998 E A ADOÇÃO DO REGIME DE CÂMBIO FLUTUANTE}

A política macroeconômica predominante do início dos anos 90 foi sendo alterada em 1996-1997 à medida que o Banco Central passou crescentemente a privilegiar o objetivo anti-inflacionário e permitia a maior apreciação real do peso e o aumento no déficit de transações correntes. O sistema de bandas cambiais foi perdendo credibilidade devido às falhas na sua administração, mas não por ser inerentemente instável (Ffrench-Davis, 2003, p. 11)

A partir da crise da Ásia em 1997, ocorreu uma significativa queda na oferta de financiamento externo para as economias emergentes. A economia chilena foi duramente atingida à medida que os países asiáticos respondiam à época por um terço das exportações e o preço do cobre sofreu forte queda. Houve uma significativa piora dos termos de troca, da ordem de $3 \%$ do PIB (Ffrench-Davis, 2007). A taxa de crescimento do PIB cai pela metade em 1998, para 3,2\%, e em 1999 atinge $-0,8 \%$ ao ano. A forte saída de capitais em direção aos países desenvolvidos, que se iniciou em 1997, intensificou-se em 1998 e 1999, com a crise na Rússia e no Brasil.

O efeito sobre o regime de bandas cambiais foi a depreciação da taxa nominal e seu afastamento do piso da banda em 1997, conforme ilustra o gráfico 2. Havia alguns temores em relação à ocorrência de uma forte depreciação da moeda chilena. Um deles era o aumento das taxas de inflação uma vez que a economia estava aquecida, e o consequente, descumprimento da meta de inflação. Outro temor era que os balanços das empresas ficassem comprometidos em função de seus passivos dolarizados.

Segundo Meyer (1998, p. 12), “a forte pressão no mercado à vista deveu-se, em parte, às posições descobertas em pesos e à ausência de mecanismos adequa- 
dos de hedge". Primeiro, o Banco Central utilizou parte de suas reservas para vender dólares no mercado de câmbio a preços artificialmente mais baixos. Em julho de 1998, a amplitude das bandas de flutuação foi fortemente reduzida de $25 \%$ para uma banda assimétrica cujo piso era $-3 \%$ e o teto, $2,5 \%$. A medida foi inicialmente bem-sucedida, mas sua credibilidade foi comprometida quando o choque negativo provocado pela crise da Rússia retomou uma forte especulação contra o peso. A partir de setembro de 1998, o intervalo da banda de flutuação foi ampliado para $7 \%$ e no final do ano para $\pm 8 \%$. A política monetária recessiva elevou as taxas de juros reais de $8,5 \%$ para $14 \%$ e visava conter as pressões especulativas sobre o peso chileno, fruto da redução dos créditos externos e da fuga de capitais de residentes. A inflação externa que corrigia o centro da banda passou a ser desconsiderada $\mathrm{e}$, assim, o centro da banda passou a ser condicionado à meta de inflação e não mais à inflação passada.

Para Rojas (2000, p. 119), o abandono do sistema de flutuações foi uma decisão acertada, uma vez que havia objetivos conflitantes e as alterações aleatórias promovidas na administração do sistema de bandas cambiais sinalizava que "la autoridad en el último tiempo mostró um grade de indefinición importante en matéria cambiaria, situación que afectó la credibilidad misma del sistema y la del Banco Central en esta matéria”.

As taxas de juros foram mantidas altas até meados de setembro de 1998, quando ficaram claros os primeiros sinais de recessão e de que a depreciação do peso não se traduziria em taxas de inflação mais elevadas. Nesse momento, o intervalo de variação da banda cambial voltou a se ampliar. Os encaixes de $30 \%$ sobre a entrada de capitais de curto prazo foram reduzidos a $0 \%$, e mantida a exigência de permanência de no mínimo um ano do investimento direto estrangeiro.

Em setembro de 1999 foi anunciada a adoção do regime de câmbio flutuante, depois que o auge da turbulência sobre a economia chilena já havia passado e a autoridade monetária estava já há alguns meses sem intervir no mercado de câmbio.

Segundo Morandé e Tapia (2002), nesse período a economia chilena já caminhava para um regime de câmbio flutuante. Várias medidas vinham sendo tomadas nesse sentido, tais como: estabelecer normas sobre descasamento entre moedas; liberalizar o mercado de derivativos e zerar a alíquota que incidia sobre a entrada de capitais estrangeiros de curto prazo. Os autores ressaltam algumas razões para o abandono do regime de bandas cambiais deslizantes. Primeiro, as taxas de inflação anuais em 1999 estavam em torno de 3\%, nível considerado como o de objetivo de longo prazo. O Banco Central passou a ter como meta manter as taxas de inflação estáveis e não mais reduzi-las. Isso significava uma mudança no sentido de aumentar a transparência e aperfeiçoamentos na forma de condução das metas de inflação. Entendia-se como aprimoramento na condução da política macroeconômica a adoção de um regime de câmbio flutuante, uma vez que os conflitos inerentes à manutenção de duas metas nominais deixariam de existir. Finalmente, a experiência de depreciação cambial entre 1998 e 1999 mostrou que o pass through da taxa de câmbio era menor do que o esperado. 
Não havia consenso em que a trajetória natural seria a adoção de taxas de câmbio flutuante, mas ganhava força a ideia de que o país deveria abandonar as políticas pouco convencionais e aderir plenamente ao regime de metas de inflação. Para Ffrench-Davis e Villar (2007), a apreciação real de $20 \%$ do peso entre março de 1995 e outubro de 1997 sinalizava que a forma de condução da política cambial foi alterada em relação ao bem-sucedido período anterior à crise mexicana. Como relatado anteriormente, alguns parâmetros do regime de bandas foram alterados aleatoriamente para permitir que a taxa de câmbio se apreciasse e fossem reduzidas as pressões monetárias em decorrência das constantes intervenções do Banco Central no mercado cambial. A consequência foi que a taxa de câmbio nominal permaneceu no período praticamente no piso e se aproximava de um regime de câmbio fixo com bandas. No final de 1997 e ao longo de 1998, quando as expectativas no mercado internacional se reverteram e os capitais de estrangeiros e chilenos passaram a deixar o país, o Banco Central atuou aumentando a taxa de juros e reduzindo a amplitude das bandas, não consentindo que a taxa de câmbio variasse dentro do sistema de bandas móvel. A atuação das autoridades monetárias indicava o desejo de evitar a depreciação e sua transmissão para as taxas de inflação. Houve perda de credibilidade da atuação do Banco Central e o regime de bandas cambiais deslizante passou a ser crescentemente questionado.

Um trabalho encomendado pelo FMI e elaborado por Eichengreen et al. (1998), para estudar estratégias de "saída" para os países que buscavam maior flexibilidade cambial, reconhece que a transição bem-sucedida do Chile foi possível graças a vários esforços como fortalecimento do setor financeiro e a manutenção de equilíbrio fiscal, além do bem-sucedido mecanismo de controles de capitais.

Segundo Fischer (2001, p. 10),

evidence from Chilean experience suggests that controls were for a time successful in allowing some monetary independence, and also shifting the composition of capital inflows towards the long end. Empirical evidence suggests that the Chilean controls lost their effectiveness after 1998.

Em termos fiscais, a economia chilena também não apresentava problemas à época, mas tinha déficits quase-fiscais, fruto do socorro aos bancos na severa crise dos anos 80 e das políticas de esterilização para tentar controlar a apreciação da taxa de câmbio. Os superávits fiscais da década de 90 foram heranças do período Pinochet, mantidos pelos governos democráticos. Cabe destacar que contribuíram para tal resultado o crescimento econômico e os preços favoráveis do cobre durante grande parte do período. Outro indicador fiscal favorável era a relação dívida total do governo sobre o PIB, que passou de $43 \%$ em 1990 para $14 \%$ em 1997. O que contribuiu para a não dominância fiscal sobre a política monetária foi a existência do Fundo de Estabilização do Cobre (FEC), criado em 1987. O cobre é o principal produto de exportação chileno, cuja exploração está em parte sob o controle do Estado. Toda vez que o preço do cobre excede um determinado nível de 
preços-base, o montante excedente é destinado ao Fundo. Os recursos do Fundo são utilizados para pagar parte da dívida fiscal. Assim, o Fundo permite ao governo chileno praticar políticas fiscais anticíclicas.

\section{CONSIDERAÇÕES FINAIS}

As evidências aqui apresentadas apontam para uma recorrente preocupação das autoridades do Chile na manutenção de um câmbio real competitivo nos anos 80 até meados dos 90 . O resultado chileno de maior crescimento associado à ausência de desalinhamentos cambiais está em linha com a literatura empírica que ressalta a importância de câmbios competitivos como uma das explicações para o relativo sucesso dos países do Leste e Sudeste Asiático nos últimos trinta anos, notadamente quando comparados ao desempenho decepcionante dos latino-americanos e africanos (ver, por exemplo, Dooley, 2003; Bresser-Pereira, 2006). Nesse sentido, a economia chilena parece ter mudado para um padrão asiático de administração cambial após a crise do início dos 80 .

Muitos economistas apontam a experiência chilena de transição voluntária do regime de bandas cambiais para o regime de flutuação durante os anos 90 como um caso de relativo sucesso no enfrentamento de turbulências internacionais. A não utilização da taxa de câmbio como a âncora nominal e instrumento para alcançar rapidamente níveis de inflação similares aos dos países desenvolvidos demonstra o aprendizado com a traumática experiência da crise dos anos 80 . As autoridades chilenas foram capazes de modificar o seu regime cambial de acordo com as constantes alterações no ambiente macroeconômico interno e externo, mantendo os objetivos finais de crescimento sustentável e taxas de inflação baixas no longo prazo. No entanto, o abandono da estratégia de administração da taxa de câmbio coincidiu com a redução das taxas de crescimento médio para 3,6\% ao ano, praticamente a metade do período anterior.

A popularidade do regime de bandas cambiais durante os anos 80 e 90 é compreensível uma vez que permite combinar a administração da política cambial com flexibilidade monetária, além de manter um instrumento para perseguir crescimento econômico. No caso chileno cabe destacar que, ao limitar a mobilidade de capitais de curto prazo, o país manteve relativa estabilidade da taxa de câmbio e algum grau de independência na política monetária. Com o regime de taxas de câmbio flutuante, o Banco Central passou progressivamente a eliminar as possibilidades de voltar a impor controles sobre as transações financeiras com o resto de mundo. Assim, o comportamento pró-cíclico e de curto prazo dos mercados financeiros internacionais e os ciclos externos passaram em grande parte a ditar as variações na taxa de câmbio, praticamente um retrocesso em termos de capacidade de realizar políticas macroeconômicas (ver Ffrench-Davis, 2007, p. 27).

Apesar de este artigo não ter como foco central o manejo da política fiscal e monetária e o papel da empresa estatal de cobre, estes são também aspectos relevantes para a compreensão da política macroeconômica do período. O bom de- 
sempenho macroeconômico do Chile nos 80 e 90 não se resume, obviamente, à política cambial praticada. Uma análise mais ampla do contexto e da política macroeconômica chilena no período em questão fugiria ao escopo do trabalho. Entretanto, a importância da política cambial como peça fundamental da sua estratégia de sucesso parece emergir da argumentação desenvolvida acima.

O exemplo do Chile torna-se ainda mais interessante se levarmos em consideração sua relativa abundância em recursos naturais, especialmente o cobre. Uma administração passiva da política econômica certamente faria com que o país agravasse ainda mais sua dependência do mercado mundial de commodities, com as já conhecidas desvantagens apontadas pela literatura de Dutch Disease (ver Williamson, 2003). O desenvolvimento de um setor de bens comercializáveis não-tradicional e uma integração mais ativa ao mercado mundial parecem ter sido pré-requisitos essenciais na trajetória de sucesso do Chile no período de taxas de câmbio administrado. Contudo, a instabilidade cambial trazida pela adoção de taxas de câmbio flutuante e o regime pleno de metas de inflação pode comprometer a estratégia de diversificação das exportações alcançada e deixar o país dependente das exportações de cobre, o que dificulta a busca de crescimento econômico com maior desenvolvimento.

\section{REFERÊNCIAS BIBLIOGRÁFICAS}

ALVAREZ, R. E. (2004) “Desempeño exportador de las empresas chilenas: alguns hechos estilizados”, Revista de la Cepal, n. 83, Agosto.

BRESSER-PEREIRA, L. C. (2006) “Exchange rate, fix, float or manage it?” Preface to Mathias Vernengo, (ed.) Financial Integration or Dollarization: No Panacea. Cheltenham: Edward Elgar.

CARDOSO, E. (2003) "Uma perspectiva macroeconômica do crescimento Brasileiro: algumas comparações internacionais", in Paulo Roberto de Almeida e Rubens Barbosa, editores, O Brasil e os Estados Unidos num Mundo em Mutação. Washington DC.

DORNBUSCH, R.; GOLDFAJN, I., e VALDES, R. (1995) "Currency crises and collapses", Brookings Papers on Economic Activity, Washington: Iss.2, p. 219 (75 pp.).

DOOLEY, M. P.; LANDAU, D., F., e GARBER, P. (2003) "An Essay on the revived Bretton Woods System”, NBER Working Paper 9971, Setembro.

DE GREGORIO, J.; TOKMAN, A.;VALDÉS, R. (2005) “Tipo de Cambio Flexible com metas de Inflación em Chile: Experiência y temas de interes”, Documentos de Política Econômica, Banco Central do Chile, n. 14, Agosto , 22p.

EICHENGREEN, B. e MASSON, P. with Hugh Bredenkamp [et.al.] (1998) "Exit strategies: policy options for countries seeking greater exchange rate flexibility", Occasional Paper, 168, IMF, Washington, DC, 48p.

EASTERLY, W. (2001) “The Lost Decades: Developing Countries' Stagnation in Spite of Policy Reform 1980-1998", World Bank.

FFRENCH-DAVIS, R. ; AGOSÍN, M. e UTHOFF, A. (1997) "Movimentos de capitais e estratégia exportadora e estabilidade macroeconômica no Chile”, in FFRENCH-DAVIS, R.; GRIFFITH-JONES, S. (org.) Os Fluxos Financeiros na América Latina, Rio de Janeiro: Editora Paz e Terra, pp. 179-219.

(2002) "El impacto de las exportaciones sobre el crecimiento en Chile”, Revista de la Cepal 76, Abril, Chile. 
, R. (2004) Entre el neoliberalismo y el crecimiento con equidad, tres décadas de política econômica em Chile, Siglo Veintiuno Editores, Buenos Aires, Argentina.

, R. (2007) Desarrollo Económico en Chile: Desafíos Hacia el Bicentenario. Serie Documentos de Trabalho, n. 270, Universidade de Chile, Diciembre. www.econ.uchile.cl/STD acesso em 28 de fevereiro de 2008

FFRENC-DAVIS, R. e LARRAÍN, G. (2003) How Optimal are the extremes? Latin American exchange rate policies during the Asian Crisis. Serie Informes y estudios especiales, 10, CEPAL, March.

FFRENC-DAVIS, R. e VILLAR, L. (2003) The Capital account and real macroeconomic stabilization: Chile and Colombia. Seminar on Management of Volatility, financial Liberalization and Growth in Emerging Economy, CEPAL, Santiago, Chile, April 24-25, 37p.

FISHER, S. (2001) "Exchange Rate Regimes: Is a Bipolar View Correct?", Paper prepared as the Distinguished Lecture on Economics in Government, at meetings of the American Economic Association, New Orleans, January.

MELLER, P. (1997) “A Política Antiinflacionária Chilena na década de 90”, in: O Plano Real e outras experiências internacionais de estabilização. Brasília: IPEA/CEPAL, p. 135-176.

MEYER, A. (1998) Nota sobre a economia chilena. Brasil. Ministério da Fazenda. Secretaria de Assuntos Internacionais. Brasília, mimeo, 40p.

MONTIEL, P.(2003) "Domestic macroeconomic management in emerging economies: lessons from the crises of the nineties", in Macroeconomics in Emerging Markets, Cambridge University Press.

MORANDÉ, F. (2001) "Exchange rate policy in Chile: recent experience", paper prepared for the Conference "Exchange Rate Regimes: hard peg or free floating?” organized by IMF Institute on March 19-20, 27p.

(2002) “A decade of inflation targeting in Chile: developments, lessons and challenges", in: N. Loayza; R. Soto (ed) Inflation Targeting: Design, Performance, Chalenges. Series on Central Banking and Economic Policies, n. 5, Santiago, Chile, pp. 583-626.

MORANDÉ, F.; TAPIA, M. (2002) "Política cambiaria en Chile: el abandono de la banda y la experiencia de flotación”, Revista Economía Chilena, vol. 5 n. 3, diciembre, pp. 67-94.

ROJAS, P. (2000) Política Monetaria y cambiaria em Chile durante los Noventa. Estúdios Públicos, 78, otoño, p. 101-135

SACHS, J.(1991) "Conflito social e políticas populistas na América Latina”, in Populismo Econômico: ortodoxia, desenvolvimentismo e populismo na América Latina, Bresser-Pereira (org.), Ed. Nobel, São Paulo.

WILLIAMSON, J. (1996) The crawling band as an exchange rate regime, lessons form Chile, Colombia and Israel, Institute for international economics, Washignton DC, October.

(2003) "Exchange rate policy and development", presented in Initiative for Policy Dialogue Task Force on Macroeconomics, Columbia University, New York.

ZAHLER, R. (1998) "El Banco Central y la política macroeconómica de Chile en los años noventa", Revista de La CEPAL n. 64, 1998. 